\title{
Experimental Organism Lymphosarcoma Neoplasm
}

National Cancer Institute

\section{Source}

National Cancer Institute. Experimental Organism Lymphosarcoma Neoplasm. NCI

Thesaurus. Code C114112.

An antiquated term referring to a malignant lymphoma that is diffused and composed of small and large lymphocytes. 